\title{
Inequality in the global incidence and prevalence of tuberculosis (TB) and TB/HIV according to the human development index
}

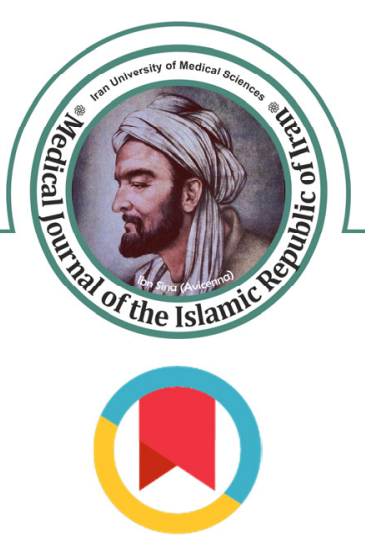

\author{
Batoul Okhovat-Isfahani ${ }^{1}$, Saeid Bitaraf ${ }^{2}$, Mohammad Ali Mansournia ${ }^{1}$, Amin Doosti-Irani*3
}

Received: 27 Feb 2018

Published: 22 May 2019

\begin{abstract}
Background: Tuberculosis (TB) is one of the ten leading causes of death, especially in developing countries. We aimed to assess the inequality in the incidence and prevalence of TB and TB/HIV based on the human development index (HDI) globally.

Methods: In this ecological study, the data on the incidence and prevalence of TB, HIV, and TB/HIV co-infection in 168 countries were obtained from the World Health Organization (WHO). The HDI of these countries in 2000, 2005, 2010, and 2015 was also obtained from the United Nations Development Program (UNDP). The concentration index was used to assess the inequality of the incidence and prevalence of TB and TB/HIV based on the HDI globally.

Results: The concentration index for the incidence of TB according to the HDI was -0.32 (95\% CI: $-0.46,-0.17),-0.36$ (95\% CI: $0.49,-0.23),-0.37$ (95\% CI: $-0.52,-0.22)$, and $-0.36(-0.52,-0.21)$ in $2000,2005,2010$, and 2015 , respectively. The same pattern was observed for the incidence and prevalence of TB/HIV. The results showed that TB and TB/HIV mainly concentrated in countries with a lower HDI.

Conclusion: According to the results of this study, the incidence of TB and TB/HIV and the prevalence of TB/HIV concentrated in the countries with a lower HDI. In addition, inequality in TB and HIV based on the HDI did not change from 2000 to 2015 . Therefore, it seems that public health programs, especially in low-income countries, should be revised and the World Health Organization and the United Nations should provide more technical and financial help for these countries.
\end{abstract}

Keywords: Inequality, Tuberculosis, HIV, Human development index

Conflicts of Interest: None declared

Funding: None

*This work has been published under CC BY-NC-SA 1.0 license.

Copyright $($ Iran University of Medical Sciences

Cite this article as: Okhovat-Isfahani B, Bitaraf S, Mansournia MA, Doosti-Irani A. Inequality in the global incidence and prevalence of tuberculosis (TB) and TB/HIV according to the human development index. Med J Islam Repub Iran. 2019 (22 May);33:45. https://doi.org/10.47176/mjiri.33.45

\section{Introduction}

Tuberculosis (TB) is one of the serious diseases that can affect all age groups (1). In 2016, 10.4 million people lived with TB, and 1.7 million died due to the disease over the word. TB is one of the 10 important causes of death in the world. More than $95 \%$ of deaths from tuberculosis occur in developing countries, of which about 0.4 million are in HIV patients. The risk of tuberculosis among people

Corresponding author: Dr Amin Doosti-Irani, a.doosti@umsha.ac.ir

1. Department of Epidemiology and Biostatistics, School of Public Health, Tehran University of Medical Sciences, Tehran, Iran

2. Department of Epidemiology, School of Public Health, Iran University of Medical Sciences, Tehran, Iran

3. Research Center for Health Sciences, Hamadan University of Medical Sciences, Hamadan, Iran, \& Department of Epidemiology, School of Public Health, Hamadan University of Medical Sciences, Hamadan, Iran living with HIV is 20 to 30 times more than HIV negative people. In 2016, about $40 \%$ of the deaths in HIV-positive people were due to tuberculosis, and it was estimated that 1.4 million new cases of tuberculosis occurred in HIVpositive people. In 2016, most of the TB cases occurred in Asia (45\%) and Africa (25\%). India, Indonesia, China, the Philippines, Pakistan, Nigeria, and South Africa are seven

$\uparrow$ What is "already known" in this topic:

The social, environmental and biological risk factors of TB are prevalent among the poor people, and these factors likely contribute to a complex web of poverty-based risk factors of the TB.

$\rightarrow$ What this article adds:

The results of our study reflect the relationship of HDI as a socioeconomic indicator with the incidence and prevalence of $\mathrm{TB}$ and TB/HIV in the world, especially in developing countries. In addition, inequality in TB and HIV based on the HDI did not change from 2000 to 2015. 
countries with the highest priority of new TB cases (1).

$\mathrm{TB}$ is preventable and treatable. However, patients may die if they do not receive proper treatment. According to the World Health Organization (WHO), TB diagnosis and treatment saved the lives of 53 million people between 2000 and 2016 (1). To put an end to the TB epidemic is one of the health targets of the Sustainable Development Goals By 2030 (1). According to an ecological view, population groups in low-income regions have more health problems (2). There is an association between socioeconomic inequality and TB and HIV morbidity/mortality $(3,4)$. Poverty is one of the determinants of tuberculosis. There is a linear association between per capita gross domestic product (GDP) and the incidence of TB (5). The level of human development index (HDI) is a strong predictor of the changes in the incidence of TB during the time in the countries (6). However, several studies show the opposite finding (7-9). Many of the social, environmental and biological risk factors of $\mathrm{TB}$, are prevalent in the poor versus the wealthier people. These factors are likely contributing to a complex web of poverty-based risk factors of the TB (10-12). HDI is a three-dimension measure including life expectancy, education, and income. In addition, HDI is one of the most important indices which indicates the level of development in each country (13). The health dimension of HDI is measured by life expectancy at birth, the education is assessed by the average number of years of schooling for people over the age of 25 , and the income is measured using the gross national income per capita (14). The HDI shows the distinction between human well-being and income. Moreover, it can illustrate a better picture of the country's development than does only income (15). The United Nations Development Program (UNDP) calculates and reports the HDI for all countries annually (14).

Assessment of inequality for the incidence and prevalence of TB and HIV according to the HDI can aid the international health organizations in designing better prevention programs to control these infectious diseases worldwide more efficiently. Based on our knowledge, no study has assessed inequality in the incidence and prevalence of TB and TB/HIV based on the human development index; therefore, this study was conducted to investigate the global inequality for the incidence and prevalence of TB and TB/HIV based on the HDI from 2000 to 2015.

\section{Methods}

In this global ecological study conducted in January 2018 , the inequality for the incidence and prevalence of TB and HIV based on the HDI was assessed in the world. The incidence and prevalence of TB, HIV, and TB/HIV co-infection were obtained from the WHO (16). We also extracted the HDI of the countries in 2000, 2005, 2010, and 2015 from the UNDP (17). The incidence and prevalence of TB, HIV and TB/HIV were available for 198 countries. HDI was available for 188 countries, and the incidence, prevalence, and HDI were available just for 168 countries. Finally, we included 168 countries in the analysis.
In this ecologic study, the prevalence of $\mathrm{TB}$ and $\mathrm{TB} / \mathrm{HIV}$ in different countries in 2000, 2005, 2010, and 2015 were the outcomes of interest. We also investigated the trend of inequality between 2000 and 2015.

Concentration index was used for assessment of the inequality of TB and TB/HIV based on the HDI. The concentration index can be calculated by the following formula:

$$
C=\frac{2}{\mu} \operatorname{cov}_{w}\left(y_{i}, R_{i}\right)
$$

Where $y_{i}$ and $R_{i}$ are the health status of the ith country and the ith country's fractional rank in terms of the HDI status respectively, and $\operatorname{cov}_{w}$ is the weighted covariance between $y_{i}$ and $R_{i}$ (18). The concentration index was weighted using the population size of the countries. The concentration index ranges between -1 and +1 . This index is commonly used in socioeconomic inequality studies (10). The negative and positive values of this index indicate the concentration of the health outcome of interest in the poor and rich population, respectively. In the case of lack of inequality, the concentration index is zero (11). The results were reported at $95 \%$ confidence interval (CI). Stata 12 (Stata Corp, College Station, TX, USA) was used for data analysis.

\section{Results}

In this ecological study, we used the data of the incidence and prevalence of $\mathrm{TB}$ and $\mathrm{TB} / \mathrm{HIV}$ as well as the HDI in 2000, 2005, 2010, and 2015 for 168 countries. Niger and Norway had the lowest and highest HDI, respectively.

The highest incidence of TB and TB/HIV was seen in African regions such as Central African Republic, Lesotho, and Swaziland. The lowest incidence of TB and TB/HIV was seen in Barbados and the United Arab Emirates. The lowest prevalence of TB/HIV was seen in the United Arab Emirates, Qatar, Jordan, and Tonga in 2000, 2005,2010 , and 2015 respectively, and the highest prevalence of TB/HIV was seen in Swaziland.

The concentration index of the incidence of TB based on the HDI was -0.32 (95\% CI: $-0.46,-0.17),-0.36(95 \%$ CI: $-0.49,-0.23),-0.37$ (95\% CI: $-0.52,-0.22)$, and -0.36 ($0.52,-0.21)$ in $2000,2005,2010$, and 2015 , respectively (Table 1). The concentration index of the prevalence of TB/HIV based on the HDI was -0.13 (95\% CI: -0.32 , $0.08)$ and -0.18 (95\% CI: $-0.33,-0.03)$ in 2000 and 2015 , respectively (Table 1$)$. The concentration index of the incidence of $\mathrm{TB} / \mathrm{HIV}$ according to the HDI was -0.53 (95\% CI: $-0.79,-0.26)$ and -0.49 (95\% CI: $-0.76,-0.22)$ in 2000 and 2015, respectively (Table 1).

Table 2 shows the concentration index of the incidence of TB, incidence of TB/HIV, and prevalence of TB/HIV based on the HDI in WHO regions. The negative values of the concentration index indicated that tuberculosis was more concentrated in countries with a lower HDI.

The results showed that the incidence and prevalence of TB in HIV and the incidence of TB were mainly concentrated in countries with a lower HDI. Moreover, the Lorenz curve, in all years, showed the concentration of the incidence and prevalence of TB in HIV-positive people living in countries with a low HDI. The same results were 
Table 1. Concentration indexes for the inequality of TB incidence, TB/HIV incidence, and prevalence of TB/HIV according to the HDI by year

\begin{tabular}{llccc}
\hline Outcome & Year & Concentration index & \multicolumn{2}{c}{$95 \%$ confidence interval } \\
\cline { 3 - 4 } Incidence of TB & & & Lower limit & Upper limit \\
& 2000 & -0.32 & -0.46 & -0.17 \\
\multirow{3}{*}{ Incidence of TB/HIV } & 2005 & -0.36 & -0.49 & -0.23 \\
& 2010 & -0.37 & -0.52 & -0.22 \\
& 2015 & -0.36 & -0.52 & -0.21 \\
Prevalence of TB/HIV & 2000 & -0.53 & -0.79 & -0.26 \\
& 2005 & -0.58 & -0.83 & -0.33 \\
& 2010 & -0.54 & -0.81 & -0.28 \\
& 2015 & -0.49 & -0.76 & -0.08 \\
\\
\end{tabular}

Table 2. Concentration indices of TB incidence, TB/HIV incidence, and prevalence of TB/HIV according to the HDI by year by WHO regions

\begin{tabular}{llcccc}
\hline Outcome & WHO regions & \multicolumn{4}{c}{ Concentration index $(95 \% \mathrm{CI})$} \\
\cline { 3 - 5 } Incidence of TB & Africa & 2000 & 2005 & 2010 & 2015 \\
& Americas & $-0.03(-0.18,0.12)$ & $0.08(-0.11,0.26)$ & $0.09(-0.11,0.30)$ & $0.07(-0.15,0.29)$ \\
& South-East Asia & $-0.47(-0.71,-0.23)$ & $-0.47(-0.73,-0.22)$ & $-0.48(-0.75,-0.21)$ & $-0.47(-0.76,-0.18)$ \\
& Europe & $-0.05(-0.05,0.15)$ & $0.05(-0.05,0.15)$ & $0.05(-0.06,0.16)$ & $0.05(-0.07,0.17)$ \\
& Eastern Mediterranean & $-0.40(-0.57,-0.21)$ & $-0.41(-0.59,-0.22)$ & $-0.41(-0.59,-0.22)$ & $-0.40(-0.57,-0.23)$ \\
& Western Pacific & $-0.01(-0.29,0.13)$ & $-0.41(-0.70,-0.11)$ & $-0.40(-0.70,-0.11)$ & $-0.38(-0.69,-0.06)$ \\
TB/HIV incidence & $0.003(-0.11,0.29)$ & $-0.30(-0.62,0.03)$ & $-0.36(-0.75,0.04)$ \\
& Africa & $0.12(-0.12,0.35)$ & $0.22(-0.04,0.48)$ & $0.22(-0.08,0.53)$ & $0.26(-0.08,0.60)$ \\
& Americas & $-0.45(-0.70,-0.19)$ & $-0.49(-0.80,-0.18)$ & $-0.51(-0.85,-0.18)$ & $-0.51(-0.85,-0.16)$ \\
& South-East Asia & $-0.02(-0.25,0.21)$ & $0.02(-0.17,0.21)$ & $0.07(-0.11,0.26)$ & $0.13(-0.11,0.37)$ \\
& Europe & $-0.18(-0.40,0.05)$ & $-0.19(-0.45,0.06)$ & $-0.40(-0.67,-0.14)$ & $-0.42(-0.71,-0.13)$ \\
& Eastern Mediterranean & $-0.43(-0.83,-0.03)$ & $-0.40(-0.70,-0.11)$ & $-0.43(-0.70,-0.16)$ & $-0.37(-0.67,-0.07)$ \\
TB/HIV prevalence & Western Pacific & $-0.55(-0.99,-0.11)$ & $-0.52(-0.94,-0.11)$ & $-0.50(-0.89,-0.11)$ & $-0.45(-0.79,-0.11)$ \\
& Africa & $0.07(-0.13,0.26)$ & $0.08(-0.11,0.26)$ & $0.07(-0.12,0.26)$ & $0.13(-0.07,0.32)$ \\
& Americas & $0.07(-0.09,0.24)$ & $0.02(-0.13,0.17)$ & $-0.12(-0.21,-0.03)$ & $-0.17(-0.26,-0.07)$ \\
& South-East Asia & $0.003(-0.24,0.25)$ & $0.03(-0.18,0.25)$ & $0.08(-0.14,0.30)$ & $0.10(-0.10,0.31)$ \\
& Europe & $0.30(0.12,0.48)$ & $0.28(0.08,0.47)$ & $0.04(-0.17,0.25)$ & $-0.03(-0.24,0.18)$ \\
& Eastern Mediterranean & $0.25(-0.23,0.73)$ & $0.22(-0.18,0.63)$ & $0.08(-0.24,0.40)$ & $0.06(-0.22,0.33)$ \\
& Western Pacific & $-0.25(-0.62,0.11)$ & $-0.22(-0.61,0.17)$ & $-0.18(-0.56,0.19)$ & $-0.11(-0.33,0.11)$ \\
\hline
\end{tabular}

seen for the incidence of tuberculosis (Figs. 1-3).

\section{Discussion}

This ecologic study was conducted to assess the inequality of the incidence and prevalence of tuberculosis based on the HDI. Our results showed that the incidence of TB, incidence of TB/HIV, and prevalence of TB/HIV were concentrated in countries with lower HDI levels. The negative values of concentration index for the TB incidence in the Americas, Europe, and Eastern Mediterranean regions of WHO was statistically significant from the year 2000 to 2015, while these values for other regions

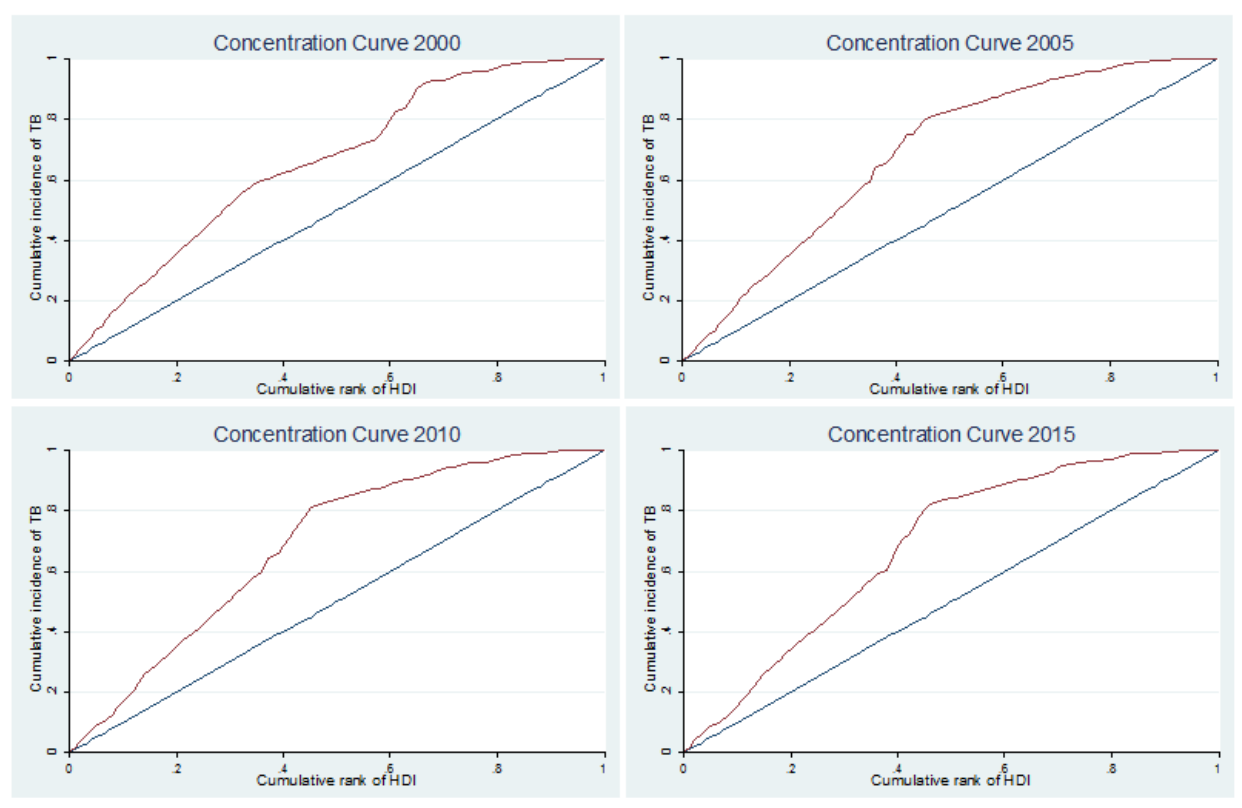

Fig. 1. Concentration curve of TB incidence based on HDI in 2000, 2005, 2010, and 2015 


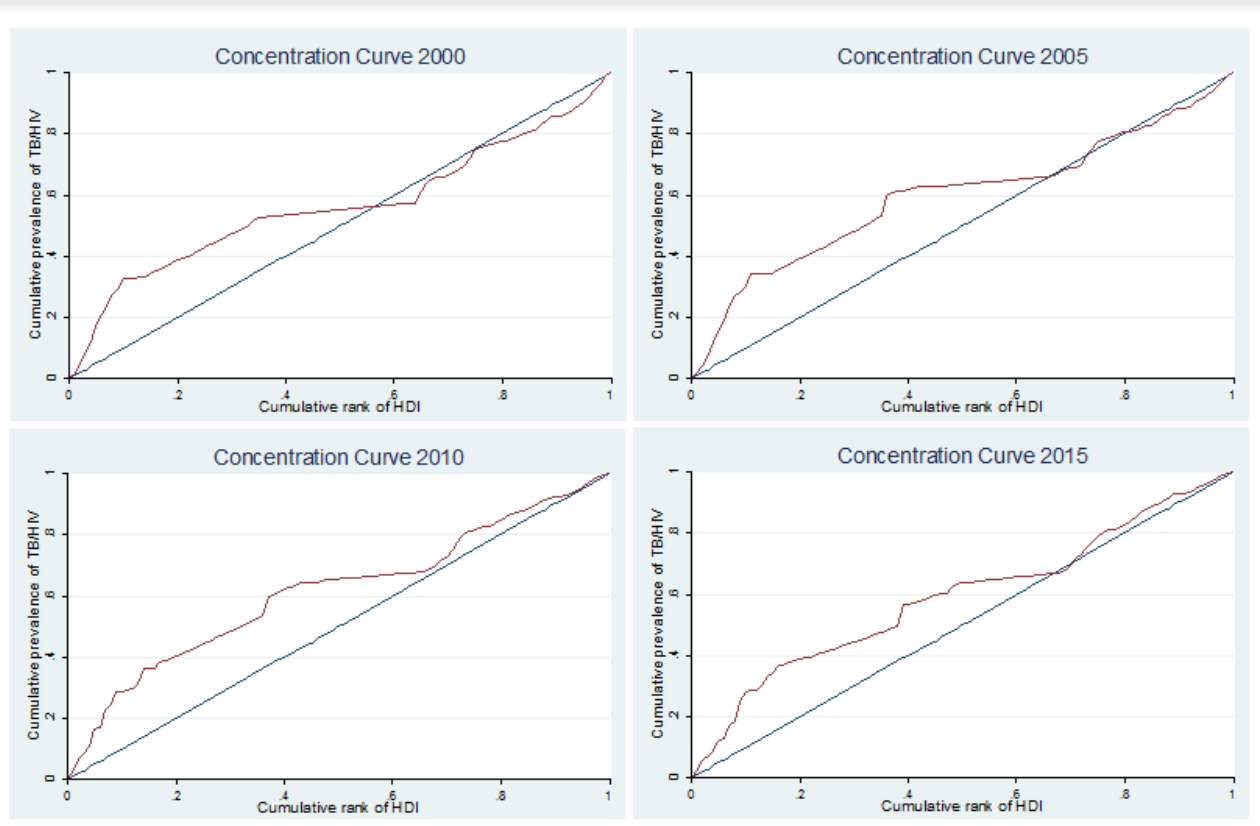

Fig. 2. Concentration curve of TB/HIV prevalence based on HDI in 2000, 2005, 2010, and 2015
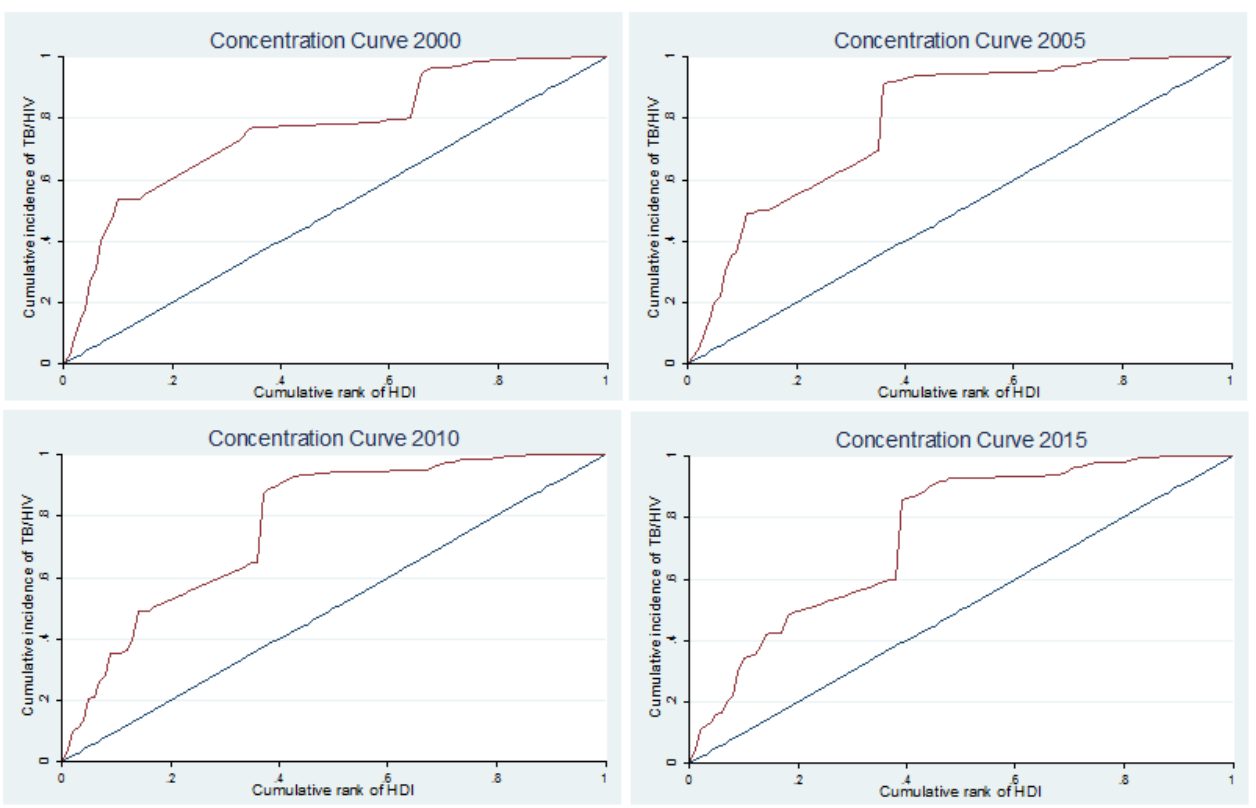

Fig. 3. Concentration curve of TB/HIV incidence based on HDI in 2000, 2005, 2010, and 2015

were not statistically significant. A reason may be due to less accurate reported data regarding the incidence of TB and HDI in undeveloped countries, especially in the Africa region. In the case of TB/HIV incidence, the negative values of concentration index for the Americas, Eastern Mediterranean, and Western Pacific regions were statistically significant. In the case of TB/HIV prevalence, the positive value of the concentration index for Europe regions was statistically significant in 2000 and 2005, but these values were not significant in 2010 and 2015. A reason for these positive values may be due to lower mortality of patients with TB/HIV in developed countries.

Our results were also consistent with the results of other studies indicating more concentration of the TB prevalence in countries with a low HDI (19-21). Another study showed inequality in the prevalence of HIV according to the HDI in 2012 (22). There is also a report of inequality in the incidence of cancer based on the HDI globally (23). The reasons for the higher concentration of TB incidence in less developed regions may be living in poor conditions such as food insecurity, inappropriate housing and lack of access to appropriate health care (24).

According to our study, the inequality-adjusted HDI of the incidence of TB decreased from 2000 to 2010 and then increased until 2015. This pattern was consistent with the prevalence of tuberculosis in HIV positive patients. A study showed that the global incidence of tuberculosis was constant from 1990 up to around 2001, and then started to decline until 2012. The rate of decline was $2 \%$ between 2011 and 2012. The incidence of TB decreased in all six WHO regions at different rates, ranging from $6.5 \%$ per year in the European region to $2 \%$ per year in Southeast 
Asia and 1\% per year in the Eastern Mediterranean (25).

We also found inequality in the incidence of TB according to WHO regions. In most WHO regions, TB and TB/HIV were more concentrated in countries with a lower HDI. According to some studies conducted in the United States and the United Kingdom, poverty, income inequalities, and lack of social capital were important predictors of increased incidence of tuberculosis $(26,27)$. In addition, our results showed inequality for the incidence of $\mathrm{TB}$ in HIV patients based on the HDI. One study showed that TB cases co-infected with HIV were more frequently seen in the African region. Overall, co-infection with HIV was seen in $37 \%$ of $\mathrm{TB}$ cases in this region, accounting for $75 \%$ of TB cases in HIV positive people worldwide (25).

Overall, our results showed that a better socioeconomic status is associated with a lower incidence and prevalence of tuberculosis. The results of this study suggest that although public policies for TB prevention have reduced the disease rate, improvement of other factors such as education and income also have significant impacts (28). Therefore, in developing countries, a control program with a public health approach is required. In fact, every effort should be made to improve the social conditions, such as reduction of the prevalence of communicable diseases.

The first limitation of our study was the use of aggregate data at the country level instead of individual data, which is an important limitation of ecological studies. This bias may occur because an association observed between variables on an aggregated measure does not necessarily indicate the association on an individual level. Therefore, the association between inequality and HDI may have different patterns and interpretations in different countries (29).

Another limitation of this study was regarding the data; we could not obtain the prevalence and incidence of TB and TB/HIV based on the age groups and sex in the countries, so we could not adjust the concentration index based on these variables.

\section{Conclusion}

Our results reflect the relationship of HDI as a socioeconomic indicator with the incidence and prevalence of TB and TB/HIV in the world, especially in developing countries. In addition, inequality in TB and HIV based on the HDI did not change from 2000 to 2015. Therefore, it seems public health programs, especially in low-income countries, should be revised and the World Health Organization and the United Nations should provide more technical and financial support for these countries.

\section{Conflict of Interests}

The authors declare that they have no competing interests.

\section{References}

1.WHO. 2017. Available from: http://www.who.int/mediacentre/ factsheets/fs104/en/.

2. Whitehead M, Dahlgren G. Concepts and principles for tackling social inequities in health: Levelling up Part 1. World Health Organization: Studies on social and economic determinants of population health.
$2006 ; 2$.

3. Gonçalves Lisbôa Pereira A, de Andrade Medronho R, Caminha Escosteguy C, Ortiz Valencia LI, de Avelar Figueiredo Mafra Magalhães M. Distribuição espacial e contexto socioeconômico da tuberculose, Rio de Janeiro, Brasil. Rev Saude Publica. 2015;49.

4. Hargreaves JR, Boccia D, Evans CA, Adato M, Petticrew M, Porter JD. The social determinants of tuberculosis: from evidence to action. Am J Public Health. 2011;101(4):654-62.

5. Janssens JP, Rieder H. An ecological analysis of incidence of tuberculosis and per capita gross domestic product. Eur Respir J. 2008;32(5):1415-6.

6. Dye C, Lönnroth K, Jaramillo E, Williams B, Raviglione M. Trends in tuberculosis incidence and their determinants in 134 countries. Bull. World Health Organ. 2009;87:683-91.

7. Boccia D, Hargreaves J, Ayles H, Fielding K, Simwinga M, GodfreyFaussett P. Tuberculosis infection in Zambia: the association with relative wealth. Am J Trop Med Hyg. 2009;80(6):1004-11.

8. Glynn J, Warndorff D, Malema S, Mwinuka V, Pönnighaus J, Crampin A, et al. Tuberculosis: associations with $\mathrm{HIV}$ and socioeconomic status in rural Malawi. Trans R Soc Trop Med Hyg. 2000;94(5):500-3.

9. Schoeman J, Westaway MS, Neethling A. The relationship between socioeconomic factors and pulmonary tuberculosis. Int J Epidemiol. 1991;20(2):435-40.

10. de Alencar Ximenes RA, de Fátima Pessoa Militão de Albuquerque M, Souza WV, Montarroyos UR, Diniz GT, Luna CF, et al. Is it better to be rich in a poor area or poor in a rich area? A multilevel analysis of a case-control study of social determinants of tuberculosis. Int $\mathrm{J}$ Epidemiol. 2009;38(5):1285-96.

11. Harling G, Ehrlich R, Myer L. The social epidemiology of tuberculosis in South Africa: a multilevel analysis. Soc Sci Med. 2008;66(2):492-505.

12. Hoa N, Tiemersma E, Sy D, Nhung N, Gebhard A, Borgdorff M, et al. Household expenditure and tuberculosis prevalence in VietNam: prediction by a set of household indicators. Int J Tuberc Lung Dis. 2011;15(1):32-7.

13. UNDP. 2014. Available from: https://www.cepal.org/en/ publications/37019-proposal-modified-human-development-index.

14. UNDP. Human Development Reports 2017. Available from: http://hdr.undp.org/en/composite/HDI.

15. UNDP. Human development report 2004 2017. Available from: http://hdr.undp.org/en/content/human-development-report-2004.

16. World Health Organization. WHO TB burden estimates [cited 03 February 2018]. Available from: http://www.who.int/tb/ country/data/download/en/.

17. United Nations Development Programme. Inequality-adjusted Human Development Index [updated 22 Mar 2016; cited 03 February 2018]. Available from: http://data.un.org/DocumentData.aspx? $\mathrm{q}=$ human + development + index\&id $=379 \# 15$.

18. Wagstaff A, Paci P, van Doorslaer E. On the measurement of inequalities in health. Soc Sci Med. 1991;33(5):545-57.

19. Castañeda-Hernández D, Tobón-García D, Rodríguez-Morales A. Association between tuberculosis incidence and the Human Development Index in 165 countries of the world. Rev Peru Med Exp Salud Publica. 2013;30(4):560-8.

20. Muniyandi M, Ramachandran R. Socioeconomic inequalities of tuberculosis in India. Expert Opin Pharmacother. 2008;9(10):1623-8.

21. Rodríguez-Morales AJ, Castañeda-Hernández DM. Relationships between morbidity and mortality from tuberculosis and the human development index (HDI) in Venezuela, 1998-2008. Int J Infect Dis. 2012;16(9):e704-e5.

22. Doosti-Irani A, Cheraghi Z, Doosti-Irani S. Inequality in the global prevalence of HIV based on the human development index. Int $\mathrm{J}$ Epidemiol. 2015;2(3):146-51.

23. Rezaeian S, Khazaei S, Khazaei S, Mansori K, Sanjari MA, Ayubi E. Human Development Inequality Index and Cancer Pattern: a Global Distributive Study. Asian Pac J. Cancer Prev. 2016;17(S3):201-4.

24. Lönnroth K, Castro KG, Chakaya JM, Chauhan LS, Floyd K, Glaziou P, et al. Tuberculosis control and elimination 2010-50: cure, care, and social development. The Lancet. 2010;375(9728):1814-29.

25. Glaziou P, Sismanidis C, Floyd K, Raviglione M. Global epidemiology of tuberculosis. Cold Spring Harb Perspect Med. 2015;5(2):a017798.

26. Arenas NE, Quintero-Álvarez L, Rodríguez-Marín K, Gómez-Marín 
Global inequality of TB and HIV

JE. Análisis sociodemográfico y espacial de la transmisión de la tuberculosis en la ciudad de Armenia (Colombia). Infectio. 2012;16(3):154-60.

27. Holtgrave DR, Crosby RA. Social determinants of tuberculosis case rates in the United States. Am J Prev Med. 2004;26(2):159-62.

28. Suk JE, Manissero D, Büscher G, Semenza JC. Wealth Inequality and Tuberculosis Elimination in Europe. Emerging Infect Dis. 2009; 15(11):1812-4.

29. Szklo M, Javier Nieto F. epidemiology beyond the basics. 2 ed. Canada: Mike Brown; 2007. 